\title{
Diaz Cintas, J. \& Nikolic, K. (Eds.) Fast Forwarding with Audiovisual Translation, Multilingual Matters, Bristol, 2018, 230 sayfa.
}

Şirin OKYAYUZ

J. Diaz Cintas ve K. Nikolic'in editörlüklerini üstlendikleri ve önsözünü yazdıkları, Fast Forwarding with Audiovisual Translation başlıklı eser, Belçika, Hırvatistan, Danimarka, İrlanda, İtalya, Polonya, İspanya, Türkiye, Birleşik Krallık ve Birleşik Arap Emirlikleri'nde farklı görsel-işitsel çeviri türleri konusunda araştırma makalelerini bir araya getirmektedir. Kitapta derlenen on iki makalede, kuramsal bir çerçevede, gerçek çeviri sorunları ve deneysel bulgular ele alınmakta ve dört altbölümde belli temalarla irdelenmektedir.

Birinci bölümdeki çalışmalarda, görsel-işitsel çeviride dilin ve kültürün aktarımı konusunda çevirmenin karşılaştıkları sorunlara odaklanılmıştır. İkinci bölümde, alımlama ve süreç araştırmalarına yoğunluk verilmiştir. Üçüncü bölümde, daha profesyonel bir bakış açısı benimsenmiş ve görselişitsel çeviri sektörünün çalışma ortamı üzerinde durulmuştur. Dördüncü ve son bölümde ise, görsel-işitsel çevirinin eğitsel ve öğretsel potansiyeli hakkındadır.

Bölümlerin altında yer alan çalışmaların tanıtımına geçmeden önce, eserin derleniş şeklini ve içeriklerin seçimlerinin ardında yatan mantığın alanda neden önemli olduğunu açıklamak yerinde olacaktır.

Dijital teknolojilerin artışıla birlikte, toplumlar, iletişim kurarken, görsel-işitsel kaynaklara geçmişte olduğundan çok daha fazla önem vermektedirler. Sinemanın doğuşu, 1950lerde televizyonun yaygınlaşması ve 1990larda internet çağına adım atılması, insanların iletişim kurma şekillerini değiştirmiştir. Kâğıttan dijital ortama geçişte ise, sadece, bilgi ve iletinin aktarım şekli değil, kullanıcıların ve alıcıların, bu evrilen ortamdaki rolleri de değişmiştir. Geçmişte, daha geleneksel medya araçları olan gazetelerle, kitaplarla veya dergilerle aktarılanlar, günümüzde görsel ve işitsel kanallarla

* Doç. Dr., İhsan Doğramacı Bilkent Üniversitesi, İnsani Bilimler ve Edebiyat Fakültesi, Mütercim-Tercümanlık Bölümü. yener@bilkent.edu.tr.

ORCID: https://orcid.org/0000-0001-7512-2764 
taşınmaktadır. Görsel-işitsel kaynaklarda, görsel ve işitsel düzgülerin 'birleşerek' bir bütün oluşturması, iki düzgüden iletilen bileşik iletinin göstergesel olanaklarını çoğalttığından, anlama ve algılamayı da olumlu yönde etkilemektedir. Dolayısıyla da, yeğlenen iletişim şekli olarak ön plana çıkmaktadır. Çeviri edimi ve uygulamaları her zaman iletişim teknolojileri ile koşut ilerlemelerle evrildiğinden, 1990'lardan itibaren görsel-işitsel çeviri uygulamalarında patlama yaşanmış ve gerçekleri evrilmiştir.

Kaynak görsel-işitsel metinlerin altyazı, dublaj, üst sesle çeviri ile farklı dillere aktarımının yanı sıra, günümüzde Sağır ve işitme engelliler için ayrıntılı altyazı, görme engelliler için sesli betimleme gibi medya ürünlerine engelsiz erişimi sağlamak için uygulamalar yaygınlaşmıştır. Gelişmeler ise, (gerek erişilen insan sayısı açısından, gerekse çevrilen içeriklerin çeşitliliği açısından) artışlara neden olduğundan, görsel-işitsel çevirinin toplumsal etkisini de arttırmıştır. Büyüyen görsel-işitsel çeviri sektörü de görsel-işitsel çeviri türlerini icra eden çevirmenlerin görünürlüğünü arttırmış, bu konuda yapılan akademik araştırma, yayın, toplantı, akademik tez, ders sayısını da çoğalmıştır. Çeviribilim altındaki akademik çalışmaların önemli odak noktalarından biri haline gelen görsel-işitsel çeviri çalışmalarında da günümüzde özellikle deneysel çalışmaların sayısında artış gözlenmektedir. Alanda yeni gelişmelerin önünü açılması için olmazsa olmaz olan deneysel çalışmalar, birçok ülkede görsel-işitsel çeviri alanında da yürütülmektedir. $\mathrm{Bu}$ deneysel çalışmaların birçoğunda da, özellikle alımlama çalışmalarına odaklanılmaktadır. Alımlama çalışmaları ile uygulayıcılar ve akademik çalışmalar yapanlar arasında bir işbirliği sürdürülmekte ve bu etkileşim sonunda da son alıcılara yönelik daha etkin ve kaliteli ürünler tasarlanması hedeflenmektedir. Görsel-işitsel çeviri araştırmalarında sıkça kullanılan göz izleme cihazları ve anket çalışmaları, söyleşiler gibi daha birçok bilişsel ve değerlendiren araç kullanılarak yapılan alımlama ve süreç çözümlemeleri ise alana büyük katkı sağlamaktadır.

Yukarıda belirtilen gelişmeler ışı̆̆ında eserde derlenmiş olan makalelerin her biri aslında belirtilen kapsamda önemli bir konuya değinmektedir. Vincenza Minutella tarafından kaleme alınan 'Globalising Bollywood: My Name is Khan' başlikla altbölümde, Amerika Birleşik Devletleri'ndeki dağıtımcıların ve İtalyan dublaj çevirmenlerinin, Hint kültürü söz konusu olduğunda, etnik ve dini kimlik konularındaki çeviri sorunsallarını nasıl ele aldıklarını incelemiştir. Araştırmacı, İtalyan izleyicilere ulaştırılan ürünlerde yenidenyazım, eyletim ve yerlileştirmenin bir güç olarak kullandığına örnek vermiştir. Marina Manifredi, 'How to be Indian in Canada, How to be Indie in Italy: Dubbing a Sitcom for Teenagers' başlıklı araştırmasında, dublaj çevirisinin gençler üzerindeki güçlü etkisini araştırmış ve bu çeviri 
yönteminin farklılıkların kabul edilmesi için önemli bir araç olduğu sonucuna varmıştır. Sattar Izwaini 'Censorship and the Manipulation of Subtitling in the Arab World' başlıklı bölümünde Arap dünyasında çeviriyi yönlendiren sansür ve eyletim mekanizmalarını örneklemiştir. Özellikle de genelleme, ikame etme ve çıkartma tekniklerinin kullanımıyla, belli kültürler için hassas olan konulardaki çeviri zorlukların nasıl giderildiğine örnek vermiştir. Kaynak metinlerde kesit dil kaymalarının, tutarsızlıkların ve iletinin edimsel içeriğinin aktarılmaması gibi yaklaşımların yoğunluğuna işaret etmiştir.

İkinci bölümde yer alan, Agnieszka Szarkowska ve diğerleri tarafından kaleme alınan 'Do Shot Changes Really Induce the Rereading of Subtitles' başlıklı çalışmada, deneysel bir yöntemle, altyazı değişmediği halde çekim geçişleri olduğu durumlarda, bunun alıcılarını altyazıları ikinci bir defa okumalarına neden olup olmadığını araştırmışlardır. Deneysel çalışmanın sonucunda ise, alıcıların altyazıları ikinci bir defa okumadıkları; ancak, hem görüntü hem de altyazıya odaklanmaya çalıştıkları için, doğal okuma ritimlerini yitirdikleri bulgusunu ortaya koymuşlardır. Bu çalışmayı takiben 'Watching Translated Audiovisuals: Does Age Really Matter' başlıklı çalışmasında Elisa Perego, farklı yaşlarda alıcıların altyazı ve dublaj çevirileri izleme alışkanlıkları ve bunun bilişsel düzeydeki etkileri ve sonuçlarını araştırmıştır. Araştırmacı alıcı yaşının alımlamayı etkilediğini ortaya koyduğu gibi, kendi araştırmasındaki eksiklikleri ele alarak yeni araştırma yöntemleri için önerilerde de bulunmaktadır. Mikolaj Deckert ise 'Content Selection and Presentation: Considerations in Interlingual Subtitling Inquiry' çalışmasında altyazı çevirisi sürecinde kaynak metinde yapılandırılan anlamın nasıl çözümlendiğini ve bunun erek metne aktarılırken nasıl yeniden yapılandırıldığını bilişsel dilbilim yöntemleriyle ele alarak açıklamıştır. 'Eye Tracking and the Process of Dubbing Translation' bölümünde araştırmacı Kristian Tangsgaard Hvelpund ise, dublaj çevirisi yapan çevirmenin göz hareketleri üzerine çalışmış ve görsel bilginin çeviri sürecinde öncelenmesinin öneminin altını çizmiştir.

Üçüncü bölümde Iwona Mazur ' Audio Description Crises Pointsd: The Idea of Common European Audio Description Guidelines' çalışmasında ADLAB projesinin bulgularını paylaşmıştır. Avrupa Birliği tarafından, ortak bir sesli betimleme kılavuzu oluşturma çabalarına destek vermek için finanse edilen projede, özellikle 'on dört sesli betimleme kriz noktası' belirlendiğini iletmektedir. Bunlardan yola çıkarak da, (sesli betimleme metni, alıcı tasarımı ve sesli betimlemenin amacı gibi konuları da kapsayacak şekilde) bir kılavuz oluşturulmasının mümkün olabileceğini ortaya koymuştur. Agnese Morettini, 'Mapping Subtitling Competence: An Empirical Study of 
Companies' çalışmasında, işverenlerin iş potansiyelleri çerçevesinde, profesyonel bir altyazı çevirmeninden beklenen becerileri derlemiştir. Bunu takiben Ali Gürkan ve Jorge Diaz Cintas 'Developing Subtitling for the Deaf and Hard of Hearing in Turkey' çalışmalarında Türkiye'de Sağır ve işitme engelliler için altyazı uygulamaları üzerinde çalışmışlardır. Altyazı çevirisinin Türkiye gibi bir ülkede yaygınlaşmasının öneminin vurgulandığı çalışmada, bunu gerçekleştirmek için öneriler de getirilmiştir.

Dördüncü ve son bölümde 'The ARDELE Project: Audio Description as a Didactic Tool to Improve (Meta)linguistic Competence in Foreign Language Teaching and Learning' araştırmasında Ana Ibanez Moreno ve Anna Vermeulen ARDELE projesini sunmuşlardır. Araştırmacılar sesli betimleme odaklı çalışmaların üstbilişsel tekniklerle öğrencilerin eğitim süreci konusunda içselleştirilmiş bilgi edinmesine nasıl yardımcı olunabileceğini örneklemişlerdir. Reglinis De Ridder ve Eithne O'Connel tarafindan kaleme alınan 'Using Audiovisual Translation to Track Language Planning Developments: Flemish Public Broadcasting Subtitles from 1995 to 2012' çalışmalarında, bütünce dilbilim yöntemleriyle görsel-işitsel çeviri araştırmalarının nasıl zenginleştirilebileceğine bir örnek sunmuşlardır. Bu tür araştırmalardan elde edilecek verilerin de toplumdilbilim, dil planlaması, azınlık medya çalışmalara gibi alanlara da katkısı olacağını ileri sürmüşlerdir.

Kısaca özetlenen on iki çalışmada görsel-işitsel çeviriye akademik, profesyonel, eğitsel bakış açılarından nasıl yaklaşılabileceği çok başarılı ve ayrıntılı bir şekilde örneklenmiştir. Farklı bölümler ve araştırmalarda ele alınan konular ise günümüzde görsel-işitsel çeviri çalışmalarında en fazla üzerinde durulan ve araştırma eksikliği görülen konular arasındadır.

Belli bir mantıkla derlenmiş ve özellikle de araştırma yoğun çalışmaların yer aldığ 1 bu başarılı eser sayesinde, ilgili araştırmacıların alana daha geniş, kapsamlı ve güncel bir bakış açısından bakması önerilmiştir. Eserin sunduğu kapsam ve bakış açısının da görsel-işitsel çeviri hakkında hâlihazırda var olan bilgimizin evrilmesine neden olacağı ve alanın bu gibi girişim ve çalışmalarla daha da zenginleşeceği ortadadır. Bu tür derleme eserler, hem dünyanın farklı yerlerindeki görsel-işitsel çeviri gerçekleri, çalışmaları ve odakları hakkında araştırmacılara bilgi aktarmaktadır, hem de potansiyel, güncel araştırma yöntemleri ve konuları hakkında bilgi sunmaktadır. Çok başarılı bir şekilde güncel konuları, odakları, yöntemleri bir araya getiren eserin, özellikle alanda deneysel araştırma yapmak isteyecekler için faydası eşsizdir. 